\title{
Three Competing Research \\ Perspectives for Oceania
}

Houston Wood

$\mathrm{C}$

urrently, three broad approaches to doing research into human phenomena are competing across Oceania. The dominant approach, introduced to the region by westerners, relies on discipline-based concepts, theories, and methods. Despite various independence and decolonization activities, disciplinary thinking still guides most formal projects and research-based publications. Though as yet considerably less common, an alternative perspective emphasizing indigenous interpretations is receiving increasing attention. This approach encourages researchers to rely on place-specific values, pedagogies, philosophies, and epistemologies unique to Pacific Islanders. A third approach, focused on concrete activities, is also available to researchers, although this perspective has as yet sparked relatively little discussion. Activities-focused research illustrates what some continental scholars call "the practice turn" (Schatzki 200I). This approach generally de-emphasizes not only disciplinary concerns but also efforts to compose interpretations.

Elements of all three approaches appear in much research focused on Oceania. Still, these perspectives differ enough to warrant thinking about them separately, especially since the choice of which to emphasize determines so much about the research process and product that follows. Epeli Hau'ofa's shifting research foci provide illustration of the impact of perspectival choice. Hau'ofa began within a disciplinary perspective, completing a dissertation and publications in anthropology, while teaching a range of social science courses at the University of South Pacific (see, eg, Hau'ofa 1975, 1977, 1981, 1987). Later, in an influential series of essays (1993, I997, 2000), Hau'ofa shifted to what I am here labeling an interpretive perspective. In this work, Hau'ofa drew more from indigenous thought than from disciplines, in part, he explained, because he could no

The Contemporary Pacific, Volume I8, Number I, 33-55

(C) 2006 by University of Hawai' $i$ Press 
longer support the consequences of such heavy reliance on continental points of view (I993). In the past few years, Hau'ofa has shifted his focus once again so that now, as director of the Oceania Centre for Arts and Culture, he emphasizes practices. While disciplines and interpretations remain a part of the work of the Oceania Centre, its primary purpose is to encourage the flourishing of contemporary visual and performing arts practices (Hau'ofa 2003, 7).

Hau'ofa's shifts in perspective also demonstrate the profound consequences that can result from choosing to emphasize one research perspective over others. Through my examination of each of these perspectives I have come to believe that, in general, Hau'ofa's and others current focus on practices is preferable to discipline- and interpretation-based approaches. This evaluation, of course, reflects my own, perhaps idiosyncratic values. I judge research in large measure on how much it seems likely to promote diversity in Oceania, as well as on how much it supports place-based autonomies. Research that encourages the vigor of differences among people, languages, and practices generally seems more valuable to me than research that has no or negative effects on Oceania's (and Earth's) threatened multiplicities.

Perhaps surprisingly, I do not evaluate research perspectives on the basis of how much they seem likely to create new knowledge, an explicit goal for many researchers. The notion that knowledge can or should grow with each new generation or project embodies what seems to me an unnecessarily narrow view of both the nature and the value of knowledge. One could as easily imagine valuing most those research projects in Oceania that restrain or reverse the so-called growth of knowledge. Many people in the region value the knowledge of their ancestors more than what is considered new. Also, much of what is called new knowledge in the region tends to silence and demean precontact knowledge systems. But whether disciplinary, interpretive, and practice approaches to research tend to encourage or discourage the growth of knowledge is irrelevant to my criteria for judging these perspectives-that is, how much they encourage diversity and autonomy in the region.

Indigenous and nonindigenous researchers with different values may rate these approaches differently. All would likely agree, however, that each researcher's choice of theories, concepts, and methods shapes the eventual results. These pages aim to help clarify the consequences of choosing a disciplinary-, interpretive-, or practice-based point of view. 


\section{The Discipline-Based Research Approach}

Discipline-based approaches introduced by colonizers still dominate professional research throughout Oceania. Indeed, there would be very little formal research in the region if all research grounded in anthropology, communication, geography, economics, education, history, political science, psychology, sociology, and cultural and literary studies were to disappear. Inertia provides a partial explanation: Since most research has been based in disciplines for many decades, it is generally easier to repeat, with variations, projects like those that have already been done. Money is also an important factor. Funding agencies both within and outside the region generally reject proposals that do not invoke disciplinary theories and terms. Discipline-based research in the region also has the advantage of enabling Oceania's researchers to communicate with other researchers who are associated with immense economies and governments on distant continents. Many well-intentioned researchers in Oceania continue with discipline-based projects to facilitate dialogue with powerful people on continents. These researchers aspire to speak disciplinary truths to power in hopes that elites will behave better toward the people in Oceania than they have in the past.

Some researchers also continue to rely on their disciplines because they believe the associated theories, concepts, and methods provide a superior way of understanding reality. Timothy Ferris has described this as the faith that researchers have "come of age in the Milky Way" (I988). Physical and life scientists now think about reality in the same ways as all mature beings throughout the galaxies, according to Ferris. In mathematics, scientists employ a conceptual system that describes reality as it must universally be described. Proponents of this view believe that mathematics is not culture bound, or even Earth bound, because mathematics is the language the universe speaks to itself.

I have doubts about such claims for mathematics and for the natural sciences, but even if accepted, these claims do not seem to justify similar claims for the contemporary humanities and social sciences. Disciplinary research into human phenomena shows little evidence of having "come of age" in the Milky Way, in Oceania, or anywhere. Language, customs, groups, beliefs, and other human processes do not speak the language of equations, to their analysts or to their producers. As a consequence, the 
theories, concepts, and methods that disciplinary researchers use to interpret Oceania remain in flux, contradictory, inconsistent, and often incoherent. Conclusions about Oceania produced within the humanities and social sciences seldom last more than a few decades. For example, four of the most commonly employed concepts today- "identity," "indigenous," "globalization," and "governance,"-were little used just fifty years ago. ${ }^{1}$ At that time, concepts such as "norms," "evolution," "development," and "race" were common, though these descriptors are now generally dismissed as outdated. Disciplinary approaches have their benefits, some of which are described above. But I do not think researchers should choose disciplinary over interpretive, practice, or other approaches on the basis of claims the human sciences possess superior ways of knowing.

Multiple critiques of discipline-based perspectives have been offered for decades, both on continents and across Oceania. Especially prominent have been Michel Foucault's descriptions of ways that disciplines function to limit the scope of possible research projects (see, eg, Foucault I980). In Oceania, writers have pointed out that disciplinary divisions of knowledge misrepresent how most Pacific Islanders customarily experience their own worlds (see, eg, Gegeo and Watson-Gegeo 200I, 2002; Meyer 2003). Disciplines that separate the spiritual from the political, literature from history, or economics from psychology, for example, misconstrue how most people in Oceania live. Resorting to interdisciplinary approaches-the remedy chosen by some-does not solve the problems associated with dividing into parts what people experience as whole.

The continuing dominance of humanities and social science research in Oceania would be troublesome, I think, even if it were clear that they do employ superior epistemologies. Every use of disciplinary concepts, theories, and methods asserts not only that continent-based perspectives provide the best ways to comprehend the people of Oceania, but also that all peoples in Oceania can be understood in much the same way. When disciplines describe differences among peoples, they do so within a universalizing frame. So Marshall Sahlins (I995), for example, wrote a book about "how 'Natives' [Hawaiians] think," not to answer questions about or for the benefit of Hawaiians, but for the benefit of anthropologists. Historians collect local histories throughout the region; literary researchers study the oral, danced, and carved literatures; anthropologists investigate religions; political scientists examine the mechanisms of governance; psychologists seek the cognitive scripts; and so on. Each assumes their dis- 
cipline has prepared them to know one aspect of Oceania's people. It is not acceptable for a discipline-based researcher to say, "Those people are so different from how I am trained to think that I cannot use concepts, methods, and theories developed elsewhere to understand them." Unless researchers accept the possibility of such incommensurable differences, however, they cannot embrace a belief the other may be fundamentally unlike the researcher, and that deep and consequential human diversity really exists.

Disciplines are part of the homogenization of the world. In asserting the ability to know, disciplines encourage their practitioners to form opinions about how others should live. Discipline-based research undermines placebased decision making about local cultural, economic, and political matters. Because expert researchers tend to believe their theories, concepts, and methods provide universally appropriate knowledge, they often feel an ethical obligation to guide local peoples when these people confront issues that researchers believe they know much about. Discipline-based researchers also tend to subscribe to the view that educated elites generally know what is best for a people, especially when momentous decisions must be made about economic investments, for example, or governmental plans.

It may be, then, that even those who believe their theories, concepts, and methods "have come of age in the Milky Way" may wish to cease producing discipline-based research. Researchers who desire an increased diversity in and local autonomy for Oceania will likely emphasize alternative perspectives.

\section{INTERPRETATION-BASED RESEARCH}

Dissatisfaction with Western-based disciplines helped spark interest in the interpretation-based approaches now increasingly embraced across Oceania. Albert Wendt elaborated some of the rationale for this perspective in his pioneering essay, "Towards a New Oceania" (I976). Related calls were also made by those promoting the "Pacific Way" and the "Melanesian Way" (see Fortune 2000; Narokobi 1980). Hau'ofa's essays, mentioned earlier, increased interest in this approach, and interpreting Oceania through the use of indigenous concepts, theories, metaphors, and myths has become common in the last decade or so. ${ }^{2}$ I have been a proponent of this approach (Wood I999, 2003), and I believe that research emphasiz- 
ing Oceania-based interpretations generally promotes diversity and placebased sovereignty in the region better than discipline-based approaches do. Nonetheless, there may be reasons to resist making interpretationbased research the new dominant perspective across the region.

There is, first, the problem that interpretations tend to be shaped by pressures for coherence. Many researchers are likely to be influenced by appeals to "rationality," and so to seek interpretations that connect logically or, at least, do not clearly contradict each other. Preferences for coherence, however, are more likely to reflect formal, written styles of thinking than the daily behaviors of the people being described. Interpretations may also be chosen for their apparent cohesiveness with other interpretations rather than for how closely they describe the phenomena observed. Interpretation-based research in general may thus tend systematically to underestimate the heterogeneity and diversity that constitute what so many believe is most valuable about Oceania (see, eg, Wendt I976; Hau'ofa I993; Teaiwa 200Ia, 200Ib).

Interpretation-based research also faces the problem that it tends to lead to broader interpretations rather than more particular ones. Generalizing narratives are often considered to explain or subsume smaller narratives. Associated with this are pressures to find a single best interpretation, as if only one interpretation, myth, or theory could be correct. This quest is delightfully illustrated in Vilsoni Hereniko's Woven Gods (I995). Though he also relied on discipline- and practice-based research strategies, Hereniko's study is primarily structured as a search for the single best interpretation of Rotuman clowning, among the many candidates provided by anthropologists, Rotumans, and Hereniko's own visions and dreams. Hereniko has produced a master interpretation that emphasizes a general Rotuman desire for harmony. His study relies on this to interpret clowning at Rotuman weddings as "a sanctioned performance by the hin mane' $\dot{a} k s u$ that is potentially subversive of the status quo" (I995, I4I). Though he acknowledged that Rotumans in general have little interest in such grand formulations ( 1995,93$)$, Hereniko used his master interpretation to explain many other activities in Rotuma as well.

Hereniko concluded Woven Gods by undermining his claims. "Do I hear a clown laughing somewhere?" (I995, I4I), he wrote, suggesting the book has been mocking his and other interpreting-selves throughout. Nonetheless, it seems to me that, more than offering comic subversions of the impulse to interpret, Woven Gods illustrates the distorting pressures 
that lead many researchers to produce generalizing stories. Even Hereniko's subsequent feature film, The Land Has Eyes (2004), appears more to offer a revised version of the master narrative developed in Woven Gods than to ridicule those researchers who seek master interpretations. Of course, composing generalizing narratives, theories, and myths may be appropriate for many writers and speakers in many situations. Those who rely principally on interpretation-based research, however, face pressures to produce master narratives even when multiple smaller interpretations may better reflect how those they are working with actually experience their worlds.

Interpretation-based research also faces a problem of impermanence. Though this type of research generally aims to produce lasting interpretations, few research-based explanations last for long. Interpretations more frequently work like utterances in conversations: one interpretation leads to others, which lead to more interpretations, and so on. Sequences of both oral and written interpretations are important, of course, but researchers who emphasize interpretations usually desire to offer more than "just talk."

George Hu'eu Sanford Kanahele's Kü Kanaka, Stand Tall: A Search for Hawaiian Values demonstrates the difficulties (I986). This book of more than five hundred pages pioneered the sort of indigenous-based interpretations that have since become more common throughout Oceania. K $\bar{u}$ Kanaka relies on diverse research methodologies to create lengthy interpretations of "traditional Hawaiian values, ... [and] uncover the essence of the Hawaiian's reason for living" (Kanahele I986, I3). Kanahele first worked with about a hundred Hawaiians, "selected as to represent a crosssection of the Hawaiian community" ( 1986 , I 8). Kanahele developed a list of twenty- five core values and then drew on extensive written and oral sources to detail the meaning of these values for traditional and contemporary Hawaiians. Along the way, Kanahele displayed impressive abilities as a researcher, writer, and interpreter.

A quote from John Dominis Holt on the back cover of the book states, "A treasure, $K \bar{u}$ Kanaka will provide us through the ages a source of mana and knowledge not previously found in a single book." In fact, however, $K \bar{u}$ Kanaka does not seem to have provided useful interpretations for even a decade, at least not for the researchers and writers with whom I am acquainted. Lilikalā Kame'eleihiwa's pathbreaking history, Native Land and Foreign Desires: Pehea Là E Pono Ai (1992), published six years after 
Kanahele's book, also offers detailed interpretations of Hawaiian values but does not mention Kù Kanaka. Nor are Kanahele's interpretations cited in later books by such influential Native Hawaiians as Manulani Aluli Meyer (2003), Jon Kamakawiwo'ole Osorio (2002), Noenoe K Silva (2004), and Haunani-Kay Trask (1999). Nonindigenous researchers have similarly ignored the interpretations offered in Ku Kanaka; for example, Marshall Sahlins composed his I995 book-length response to Gananath Obeyesekere's 1992 volume contrasting Hawaiian and European values without referencing Kanahele's earlier work.

In the natural sciences, as I have suggested, one may be able to create cumulative formulations, but new interpretations of human actions in Oceania and beyond will likely be composed by new interpreters again and again. Later researchers' disinterest in Kanahele's long book seems typical of the fate of most research-based interpretations. "Each age," as Ralph Waldo Emerson famously declared, "must write its own books" ( I 837). In the world of research interpreters, ages seldom seem to last even ten years.

These problems-the pressures for coherence, the tendency to seek meta-narratives, the absence of cumulativeness-are troublesome, but not, I think, as serious as a fourth difficulty associated with interpretationbased projects. Researchers are generally not interested in interpretations as an end in themselves but rather as ways of explaining concrete human activities. Unfortunately, there is no clear relationship between interpretations and actual behavior. Getting an interpretation "right" does not provide definite knowledge about any specific action. Interpretations are often treated as causes, but this is based more on faith than on analysis or evidence. So, for example, no specific navigational, burial, dance, or other cultural practices can be derived from Kanahele's or anyone's interpretation of Native Hawaiian values. After one observes a practice, it may be possible to say whether it fits an interpreted value. The reverse is not true, however; if one does not know a particular practice-if it is "lost" - then knowing its "values" will not lead to its recovery.

Elise Huffer, alone and in collaboration with Ropate Qalo, is one of the few researchers in Oceania who has tried to formulate how interpretations may be connected to concrete behaviors (see Huffer 2005; Huffer and Qalo 2004). Like many in Oceania who are calling for more emphasis on interpretation-based approaches, Huffer began by rejecting disciplinary approaches because they reflect not a universal but only one particular cul- 
tural view. Instead, Huffer called for researchers in the region to work at helping people interpret and articulate their "political values and ethics" $(2005, \mathrm{I} 33)$. Huffer articulated her perspective on the link between interpretations and actions. Using Samuel Fleischacker's phrase (I994, I 5), she wrote: "Ethics should be seen as an 'action-guiding code' . . constituted by people's values, which are in turn nourished by their histories, traditions, and the changes they have experienced" (Huffer 2005, I3I). According to Huffer, histories, traditions, and experience produce values; values lead to ethics; and ethics in turn direct the "action-guiding codes" that shape everyday behaviors. Constructing accurate interpretations of existing ethics and codes is important for Huffer because she believes these interpretations describe the causes of specific practices.

Huffer's work clearly states what I suspect is a common view among many researchers in Oceania. This view-that values and ethics produce codes that in turn cause behaviors-may be shared as well by many laypeople in the region. Still, I do not think it provides a master theory of behavioral causation that researchers should embrace uncritically. Interpretations about why people do what they do are probably better decided in the field, in consultation with the people studied.

Huffer and Qalo have also argued that Oceania's philosophies act as "building blocks" (2004, I07, II6). Even this less specific claim, however, seems to me to grant too much power to interpreted ideas. Building in part on Qalo's earlier research into the establishment of the Mucunabitu Iron Works Cooperative Society in Fiji (Qalo 1997), Huffer and Qalo suggested that four values might be "common among many of us who call ourselves Pacific Islanders." These values are veilomani, veikauwaitake, veivakaliuci, and veidokai, Fijian words Huffer and Qalo interpreted respectively as (I) a genuine concern for one another; (2) caring and expressing concern for the well-being of others; (3) placing others ahead of oneself; and (4) honoring, respecting, and upholding someone (2004, I08). But it seems unlikely to me that any of these four or any other interpretations of Pacific values name causes of any specific behaviors. Even if interpreters were to agree, for example, with Huffer and Qalo's formulation of veilomani as "a genuine concern for one another," this formulation does not seem to name a "building block" from which any particular action would emerge.

Huffer and Qalo's interpretations of Fijian values recall interpretations of Christianity. This now widely disseminated tradition has also promi- 
nently been claimed to be rooted in the value of "a genuine concern for one another," a phrase often further interpreted by Christians to mean "love thy neighbor as thyself." This and other supposed "core values" of Christianity, however, have not regularly acted as building blocks for any particular practices, no matter how or by whom the values have been interpreted. Christian core concepts of "love" have been claimed as cause for many horrendous as well as for many benevolent acts. It seems a mistake in general, I suspect, to think that philosophies, values, beliefs, ideals, concepts, or codes are the source of particular actions. Interpretations display culture-bound understandings of practices; they do not produce them.

\section{Practice-based Research}

Through its focus on repetitive actions, practice-based research escapes most problems associated with both discipline- and interpretation-based perspectives. As mentioned, the Oceania Centre for Arts and Culture offers one prominent illustration of this approach (Hau'ofa 2003), but some interest in practices has been part of most discipline- and interpretation-based projects for as long as there has been formal research in Oceania. In shifting their emphases to practices, then, most researchers will not have to learn new methods so much as to modify the thrust of their current and future projects.

While interpretation-based research views abstract principles, philosophies, values, beliefs and the like as causes of behaviors, a practice-based perspective treats each interpretation as but one among many types of practice. Practices are researched not to help answer academic questions, as they are in discipline-based research. Nor are practices used as the basis for formulating abstract descriptions or analyses, as they are in interpretation-based approaches. Researchers who emphasize practices consider the activities of everyday life important enough by themselves to justify lifetimes of study.

Hau'ofa's transformation from social scientist and interpreter of the region into facilitator of practices is emblematic of the change in research emphasis I am recommending. At the Oceania Centre for Arts and Culture, Hau'ofa and his colleagues are not much interested in either the disciplines of art history and instruction or in formal interpretations of how their work fits into Pacific traditions. People at the Oceania Centre instead 
learn mostly through "observation and hands-on experience" (Hau'ofa $2003,8)$. In a cooperative setting, the Oceania Centre encourages "different kinds of music, dance, art, ceremonies, and other forms of cultural production" (Hau'ofa 2003, I7). "Painters, sculptors, dancers and musicians interact with and help each other" in ways that recall those Oceanic communities where the arts are a "matter of community-wide participation" (Hau'ofa 2003, 7, 8).

Because the Oceania Centre is figuratively (and almost literally) a world unto itself, it may not be a practical model for most aspiring practice researchers. More typical of the practice-based approach in the region is the research of many who self-consciously engage in commingling contemporary and traditional practices. Prominent examples are described in Linda Tuhiwai Smith's Decolonizing Methodologies (1999), which examines Māori and other indigenous research practices; David Welchman Gegeo's several studies focusing on the knowledge practices of one group of Solomon Islanders (I994, I998; with Karen Watson-Gegeo 200I, 2002); Manulani Aluli Meyer's reports on Native Hawaiian epistemological practices (200I, 2003); as well as others, a few of which are discussed later in this article. Though the range of existing research is impressive, it likely marks but the beginning of much more practice-based work to come.

Practices are patterned activities that can be recognized as normal and repeatable by the people who enact them. Practice-based research thus may focus on any practices found along a continuum from the informal to the formal. While informal practices may seldom be discussed self-consciously, formal practices often provoke analysis and debate by the people involved in their production. Some recent research into Hawaiian burial protocols illustrates the important work possible at the formal end of the practice continuum. Carolyn Kēhaunani Cachola-Abad and Edward Halealoha Ayau have explained that caring for ancestral remains and burial sites has become increasingly important for contemporary Hawaiians (1999). Some view these sites and their associated objects as relics from the past and thus valuable primarily as opportunities for learning history. Others, however, treat these same sites and funereal objects as places of continuing obligation where traditional burial practices should be enacted. Through strictly following traditional protocols, it is believed "the ancestral foundation is strengthened, the interdependence between past and present continues, and the land is reinfused with mana necessary to sustain the ancestors, the living and the generations to come. Ola nā iwi, the 
bones live" (Nihipali 2003, B-I; see also Ayau and Tengan 2002). Practice-based researchers can assist with the enactment of rituals, protocols, and similar formally prescribed behaviors in Hawai'i and throughout Oceania.

Practice-based research, however, will likely focus more often on the more common sets of informal practices associated with different peoples and places. Such practice-based research was extremely useful, for example, in the construction, launching, blessing, and navigating of the voyaging canoe Hōkūle $a .^{3}$ In the decades since it first sailed, the Hókūle' $a$ and its newer companion, Hawai'iloa, have themselves become important research sites for further study of ocean-related practices. This and most other practice-based research demonstrates that, while something may be learned through creating interpretations, such "knowledge is meaningless unless practiced" (Ayau and Tengan 2002, I 85). Enacting practices, as in caring for the dead, building canoes, and navigating the seas, offers much to the people of Oceania, whether accompanied by interpretations or not.

Perhaps once a practice-based perspective becomes more prominent, earlier discipline- and interpretation-based research about Oceania will be revisited and found to be valuable in new ways. Hereniko's Woven Gods (I995), mentioned earlier, for example, may one day be appreciated most for its descriptions of Rotuman clowning practices. Years from now, few may turn to Woven Gods to learn what anthropologists once thought about Rotumans, or to read Hereniko's master narrative explaining Rotuman behavior. In the future Rotumans and others may wish to know more about what Rotumans did in the twentieth century that distinguished them from other humans. Then Woven Gods' recounting of clowning practices may provide a treasure trove of information about behaviors that can be learned nowhere else.

\section{The Practice Turn}

The increasing interest in practice-based research in Oceania reflects a broader transformation that Theodore R Schatzki, Karin Knorr Cetina, and Eike von Savigny labeled a "practice turn in contemporary theory" (200I). Those who emphasize practices generally reject the assumption that people live within self-organizing "systems" of beliefs, values, norms, and symbols. As Ann Swidler wrote, practice-based perspectives conceive of culture less "as a great stream in which we all are immersed and more 
as a bag of tricks or an oddly assorted tool kit containing implements of varying shapes that fit the hand more or less well, are not always easy to use, and only sometimes do the job" (200I, 24).

Swidler further explained: "This image suggests that culture cultivates skills and habits in its users, so that one can be more or less good at the cultural repertoire one performs . . . like the pieces a musician has mastered or the plays an actor has performed. It is in this sense that people have an array of cultural resources upon which they can draw. We ask not only what pieces are in the repertoire but why some are performed at one time, some at another" (200I, 24-25). Different members master each aspect of the cultural repertoire to widely varying degrees. Every culture's members, in addition, exhibit unstable commitments to enacting their bag of tricks. They make diverse and often unpredictable choices about when and how to use the oddly assorted ensemble of practices available to them.

In Oceania today, of course, cultural repertoires include many practices introduced from continents. So, for example, in the Rotuman weddings that Hereniko described, Western wedding practices appear side by side with traditional ritual clowning. Similarly, Smith, Gegeo, and Meyer's separate studies of Pacific Islander practices (mentioned earlier) demonstrate that continental and Oceanic practices are often simultaneously available for use. This intermingling of practices with diverse origins constitutes an important focus for the region's emerging practice studies.

Teresia K Teaiwa's $\mathrm{PhD}$ dissertation provides one approach for researching the mixed repertoire of practices that characterizes Oceania today (200Ia). Teaiwa focused on how practices may be articulated, disarticulated, and rearticulated in different places throughout the region. While in some earlier studies Teaiwa emphasized Foucauldian notions of opposition and resistance, her dissertation claims that, more often, Pacific Islanders throughout Oceania actively appropriate and transform old colonialist practices, adding them to their repertoires in ways that make them "their own." Teaiwa detailed, for example, how some native hierarchical practices based on race, caste, religion, and gender have been articulated with Western militaristic practices to create new, Oceanic-specific cultural ensembles. Teaiwa also explored ways that traditional Pacific Islander practices-for example dancing and ceremonial drinking-have been articulated with Western touristic practices to integrate the "old ways" within new places. ${ }^{4}$

Views of practices in Oceania as articulated, disarticulated, and reartic- 
ulated highlight what Teaiwa has repeatedly referred to as the "fluid, multiple and complex" nature of Pacific cultures (see, eg, Teaiwa 200Ia, 77), a view that resonates with Swidler's description of practice repertoires (200I). In cultures thus conceived, no "natural" connections, no basic beliefs, values, principles, or philosophies, and no master interpretations, reside in any imagined "core" of a people's way of life. Teaiwa's articulation model thus diverts the practice-based researcher's attention away from worries about "authenticity" to study instead how ensembles of diverse practices get connected, disconnected, and sometimes reconnected, through both conscious and accidental choices made by people engaged together in specific, historical contexts.

Thinking of people as defined by their practices also has the advantage of making it easier to think about similarities and differences between diasporic Oceanic groups and those who have remained nearer to their ancestral islands. Place of residence can have greater or lesser impact on a person's available ensemble of practices.

\section{Interpretations as Practices}

Because interpretation is itself a type of practice, embracing practice-based research does not end either research-based interpretations or studies of the interpretations of others. The practice perspective does, however, shift the emphasis from internal meanings to embodied external activities, that is, from conceiving of interpretations as individual and psychological to examining them instead as performances and behaviors. For practice researchers, interpretation is but one among many acts available within a dynamic cultural repertoire. It is for the people themselves, and not researchers, to decide the relative importance of interpretive and noninterpretive practices within each occasion of their use. Of course, researchers are usually more skilled at producing interpretations than at enacting many types of noninterpretive practices. Their mastery of interpretive practices enables researchers to advance in school and in their professions. It is a mistake, however, for researchers to assume that interpretations in general are more important for most people than are noninterpretive practices. In some contexts, people may treat interpretations as being as consequential as they seem to be in a social science or humanities seminar room. For those same people at other times, however, noninterpretive practices will be much more significant. 
Ty Kāwika Tengan's PhD dissertation provides a useful example of one way to apply a practice-based perspective to researching interpretations (2003). Tengan reported on a group of approximately twenty-five to thirty-five Native Hawaiian men, the Hale Mua, of which he is a member. These men have been working for over a decade at redefining what it means to be Hawaiian. Drawing on his own experiences, as well as on formal and informal interviews, Tengan's work offers a thick description of the group's evolving repertoire of interpretive and noninterpretive masculinity practices.

Tengan's discussion of the discursive or interpretive practices performed by the men of the Hale Mua generally uses a Hawaiian word, "mo'olelo," which refers to stories, tales, myths, histories, literature, legends, narratives of any length, accounts, and all coherent successions of talk (Tengan 2003, 355). Newcomers to the Hale Mua are taught several forms of mo'olelo practices, as well as how to recognize appropriate occasions for producing them. Tengan's work occasionally adopts aspects of an interpretation-based perspective in explaining the meaning of these mo'olelo, but its principle emphasis treats mo'olelo as embodied practices. Tengan has detailed how the prescribed forms of mo'olelo perform essential identity work for the men. So, for example, telling personal stories in distinct ways at the correct moments helps transform the members from "ordinary" Hawaiian-Americans into a powerful group of contemporary Hawaiian men. As Tengan explained, speaking the appropriate mo'olelo at the correct times creates connections between the men and "the land, the ancestors, and the larger Hawaiian lāhui (people/nation)" (2003, $328) .5$

The men of Hale Mua also enact noninterpretive practices that, like their prescribed mo'olelo practices, help to separate them from men who do not participate in the group. Common noninterpretive practices include types of exercise, martial arts, sparring, dance (ha'a, not hula), ritual, chanting, praying, and woodcarving. For group members, these practices manifest what it is to be a Hawaiian male. So, for example, Tengan explained, "In the case of carving, they [the Hale Mua leaders] constantly reiterate that we are not only making a weapon but also perpetuating Hawaiian culture and carrying on the knowledge of our kūpuna [elders]. Thus the importance lies not in what shape the wood ends up taking but rather [in] the fact that we go through the process and in so doing make our own mana" $(2003,230)$. The practices are constitutive of a living cul- 
ture, not a memorial to one that is past, or a symbolic representation of its meaning. Through enacting the prescribed repertoire, members of Hale Mua transform themselves into a new type of Hawaiian man.

Tengan has shown that interpretive and noninterpretive practices work similarly for participants. Though the Hale Mua puts a greater emphasis on noninterpretive practices, both types are considered necessary. Sometimes the two types are enacted sequentially: members may first carve or chant, for example, then practice mo'olelo. Sometimes, too, interpretive and noninterpretive practices intertwine, as during awa (kava) ceremonies, when ritual drinking and mo'olelo practices are performed together. At such times, interpretive and noninterpretive practices enrich one another, and a mingling of interpretations and embodied actions is indeed much valued in the group. Kyle Ka'ohulani Nākānelua, one of the leaders of the Hale Mua, explained in his interview with Tengan: "The elders have a language based on living what they [do], and speaking what they do. And so fortunately my grandmother is a native speaker, and they have a whole different way of thinking, and the language brings life to da work, and den da work gives life to da language, and when you separate the two, you lose something in da process" (2003, 298; emphasis in original). Nākānelua's comments seem to suggest that noninterpretive practices invigorate language, mo'olelo, and interpretations. When the latter are separated from material practices, the cultural repertoire is dangerously weakened.

Tengan's work shows how both the men of the Hale Mua and Tengan himself as a researcher deploy interpretive and noninterpretive practices as enactments of culture. Tengan has thus illustrated one way researchers can study interpretations in Oceania without falling back on an interpretation-based approach. His study is useful as well in the exemplary way it articulates itself as an interpretive practice. Tengan's descriptions of most of the practices of the Hale Mua are not enactments of these practices themselves. His writing about carving, ritual, or dancing, for example, offers interpretations of embodied actions, but does not reproduce those practices. His dissertation does, however, enact one Hale Mua practice: it is a mo'olelo, and one that Tengan hopes many in the Hale Mua will recognize as participating in the succession of storytellings the group encourages.

Tengan described his research mo'olelo as "only a fragment of the story, one that is told differently by each of the members that add their words to it. Yet it is one that would not exist without this multiplicity of voices and 
experiences, and it is in the collective telling that we make our mo'olelo live" $(2003,345)$. Other reports of practice-based research, including this essay, can be similarly understood as performances that draw selectively from a collectively available repertoire. Practice-based reports do things within the communities in which they appear. So, as Tengan explained, the draft form of his mo'olelo research report provoked much discussion, more mo'olelo, within the Hale Mua. In the best of circumstances, other practice-based reports will call forth similarly enriching responses from the communities with which they are shared.

\section{Emphasizing Practices}

Not all people in Oceania or elsewhere likely deploy a worldview like that of the men of the Hale Mua, who conceive of practices much as practice-based researchers do. Still, practice-based research can be adapted for cultural repertoires dominated by interpretations, for repertoires that emphasize noninterpretive actions, as well as for repertoires that feature diverse mixes of the two.

My own choice of approach reflects a commitment to cultural diversity and local autonomy, values other researchers may not share. My choice also reflects my position as a settler intellectual in the nation of Hawai'i ${ }^{6}{ }^{6}$ Though the examples I rely on here are primarily drawn from Pacific Islander researchers, I hope it does not seem that I am continuing the tradition whereby outsiders tell the native people of Oceania what they should do. I emphasize research by indigenous scholars because this work seems generally both the most exciting and the most valuable now available in the region. Restricting my examples to nonindigenous researchers might have implied that the work of indigenous researchers is not as worthy of academic study.

I mentioned earlier that some people in Oceania continue their discipline-based research in part because they believe that this discourse helps facilitate dialogue with powerful people on continents. Practice-based research may also increasingly encourage such dialogue, as more and more continental analysts are beginning to accept the idea that "Culture is a verb, not a noun, a process, not a thing in itself" (Niezen 2003, 6). Understanding culture as a dynamic process encourages research into cultures conceived of as collections of practices. Practice-based researchers in Oceania will be able to talk to researchers around the world, but their conver- 
sations will center mostly on the articulation, disarticulation, and rearticulation of practices, rather than on disciplinary or interpretive concerns.

Magnificently, the human inhabitants of Oceania are not alone in enacting practices here. Ancestors, spirits, gods, animals, fish, waves, winds, plants, stars, even places, as well as many other entities, manifest their own interpretive and noninterpretive practices. Shifting the focus of research from disciplines and interpretations to practices may enable researchers in the region to integrate the human and the nonhuman into single, unifying projects. The natural and human sciences, then, would no longer work separately, nor would researchers need to squirm when Oceania's people point to invisibles as palpable presences. ${ }^{7}$

Few research approaches are likely to be pure; most will likely mingle the three perspectives described here, to greater or lesser degrees. Still, projects tend to emphasize a single perspective, so I hope these pages encourage researchers to better understand that the disciplinary, interpretive, and practice approaches promote not merely different ways of doing research, but different futures for Oceania as well.

\section{Notes}

I "Identity" was first widely used in the I96os by social scientists in capitalist countries as a part of their attacks on communism (Medovoi 2003); the concept of "globalization" owes much to some incidental amateur photographs made by the Apollo astronauts (Cosgrove I994); both "indigenism" and "governance" became common as part of a general reconceptualization of the world by elites that took place after the collapse of the Soviet empire made their earlier binary schemes obsolete (Niezen 2003).

2 Linda Tuhiwai Smith provided an excellent summary of much of the work, especially by Māori researchers (1999). See also Wood (2003) and the later discussion for references to some interpretation-based research published after I999.

3 Information and valuable reprinted articles can be accessed from the Polynesian Voyaging Society homepage at $<$ http://www.pvs-hawaii.com/index.html>.

4 Tengan's dissertation offers a related analysis of the articulation of Native Hawaiian warrior and sports practices into colonial figurations of masculinity (2003; see especially pages 64-79).

5 Geoffrey M White provided general descriptions of the importance of interpretive practices in enacting identities in Oceania (I99I, 2000). Kame'eleihiwa 
(I992), Osorio (2002), Silva (2004), and Kanalu G Terry Young (I998) have also detailed ways that Hawaiians use mo'olelo in producing their culture.

$6 \mathrm{~J}$ Kēhaulani Kauanui has provided a useful overview of the relationship between the United States and the sovereign nation of Hawai'i (2005).

7 Suggestions about how researchers can integrate research into the human and nonhuman can be found in the writings of Hau'ofa (eg, I993, 2000), of course, as well as in work by continental thinkers such as Bruno Latour (I993, I999) and Donna Haraway (I99I). Also see the suggestions contained in several of the essays about "spirits" in Oceania in Jeannette Marie Mageo and Alan Howard's I996 volume on that topic.

\section{References}

Ayau, Edward Halealoha, and Ty Kāwika Tengan

2002 Ka Huaka'i O Nā'Ōiwi: The Journey Home. In The Dead and Their Possessions: Repatriation in Principle, Policy and Practice, edited by Cressida Forde, Jane Hubert, and Paul Turnbull, I7I-I 89. New York: Routledge.

Cachola-Abad, Carolyn Kēhaunani, and Edward Halealoha Ayau

I999 He Pane Ho'omālamalama: Setting the Record Straight and a Second Call for Partnership. Hawaiian Archeology 7:74-82.

Cosgrove, Denis

I994 Contested Global Visions: One World, Whole-Earth, and the Apollo Space Photographs. Annals of the Association of American Geographers 84:270-294.

Emerson, Ralph Waldo

I837 The American Scholar. Address to the Phi Beta Kappa Society at Harvard. I 3 August.

Ferris, Timothy

I988 Coming of Age in the Milky Way. New York: Morrow.

Fleischacker, Samuel

I994 The Ethics of Culture. Ithaca: Cornell University Press.

Fortune, Kate

2000 The Pacific Way. In The Pacific Islands: An Encyclopedia, edited by Brij

V Lal and Kate Fortune, 486-487. Honolulu: University of Hawai'i Press.

Foucault, Michel

I980 Power/Knowledge: Selected Interviews and Other Writings, I9721977. New York: Pantheon. 
Gegeo, David Welchman

I994 Kastom and Bisnis: Toward Integrating Cultural Knowledge into Rural Development in the Solomon Islands. PhD dissertation, Department of Political Science, University of Hawai'i.

I998 Indigenous Knowledge and Empowerment: Rural Development Examined from Within. The Contemporary Pacific I0:289-3I 5.

Gegeo, David Welchman, and Karen Ann Watson-Gegeo

200 I "How We Know": Kwara'ae Rural Villagers Doing Indigenous Epistemology. The Contemporary Pacific I 3:55-88.

2002 Whose Knowledge? Epistemological Collisions in Solomon Islands Community Development. The Contemporary Pacific I4:377-4I I.

Haraway, Donna

I99I Simians, Cyborgs, and Women: The Reinvention of Nature. New York: Routledge.

Hau'ofa, Epeli

I975 Anthropology and Pacific Islanders. Discussion Paper 8. Port Moresby: Institute of Papua New Guinea Studies.

I977 Our Crowded Islands. Suva: Institute of Pacific Studies, University of the South Pacific.

I98I Meke: Inequality and Ambivalence in a Village Society. Canberra: Australian National University Press.

I987 Introduction to Pacific Societies: Introduction to the Course and Assignments. Revised edition. Suva, Fiji: Extension Services University of the South Pacific.

I993 Our Sea of Islands. In A New Oceania: Rediscovering Our Sea of Islands, edited by Epeli Hau'ofa, Eric Waddell, and Vijay Naidu, 2-I6. Suva: University of the South Pacific.

I997 The Ocean in Us. Dreadlocks in Oceania I:I 24-I48.

2000 Epilogue: Pasts to Remember. In Remembrance of Pacific Pasts: An Invitation to Remake History, edited by Robert Borofsky, 453-47I. Honolulu: University of Hawai'i Press.

2003 Our Place Within: Foundations for a Creative Oceania. Forge Memorial Lecture, Australian National University, Canberra, 8 October.

Hereniko, Vilsoni

I995 Woven Gods: Female Clowns and Power in Rotuma. Pacific Islands Monograph Series I7. Honolulu: University of Hawai'i Center for Pacific Islands Studies and University of Hawai'i Press.

2004 The Land Has Eyes. Feature film. Honolulu: Te Maka Productions. Huffer, Elise

2005 Governance, Corruption, and Ethics in the Pacific. The Contemporary Pacific I7: I 8-I40. 
Huffer, Elise, and Ropate Qalo

2004 Have We Been Thinking Upside-Down? The Contemporary Emergence of Pacific Theoretical Thought. The Contemporary Pacific 16:87I I 6.

Kame'eleihiwa, Lilikalā

I992 Native Land and Foreign Desires: Pehea Là E Pono Ai. Honolulu: Bishop Museum Press.

Kanahele, George Hu'eu Sanford

I986 Kü Kanaka, Stand Tall: A Search for Hawaiian Values. Honolulu: University of Hawai'i Press.

Kauanui, J Kēhaulani

2005 Precarious Positions: Native Hawaiians and US Federal Recognition. The Contemporary Pacific 17: $1-28$.

Latour, Bruno

I993 We Have Never Been Modern. Cambridge: Harvard University Press.

1999 Pandora's Hope: Essays on the Reality of Science Studies. Cambridge: Harvard University Press.

Mageo, Jeannette Marie, and Alan Howard, editors

I996 Spirits in Culture, History, and Mind. New York: Routledge.

Medovoi, Leerom

2003 Age and the Repressed Origins of Identity Discourse. Paper read at Cultural Studies Association (US) Conference, Pittsburgh, Pennsylvania, 5-8 June.

Meyer, Manulani Aluli

200 I Our Own Liberation: Reflections on Hawaiian Epistemology. The Contemporary Pacific I3:I 24-I 48.

2003 Ho'oulu: Our Time of Becoming. Honolulu: 'Ai Pohaku Press.

Narokobi, Bernard

I980 The Melanesian Way. Boroko, PNG: Institute of Papua New Guinea Studies.

Niezen, Ronald

2003 The Origins of Indigenism: Human Rights and the Politics of Identity. Berkeley: University of California Press.

Nihipali, Kūnani

2003 Removing Bones and Burial Items Was an Act of Theft, Disrespect. Honolulu Advertiser, 25 May.

Obeyesekere, Gananath

1992 The Apotheosis of Captain Cook: European Mythmaking in the Pacific. Princeton: Princeton University Press.

Osorio, Jon Kamakawiwo'ole

2002 Dismembering Lähui: A History of the Hawaiian Nation to I887. Honolulu: University of Hawai'i Press. 
Qalo, Ropate

I997 Small Business: A Study of A Fijian Family-The Mucunabitu Iron Works Contractor Cooperative Society Limited. Suva: Mucunabitu Education Trust.

Sahlins, Marshall

I995 How "Natives” Think: About Captain Cook, For Example. Chicago: University of Chicago Press.

Schatzki, Theodore R

200I Introduction: Practice Theory. In The Practice Turn in Contemporary Theory, edited by Theodore R Schatzki, Karin Knorr Cetina, and Eike Von Savigny, I-I4. New York: Routledge.

Schatzki, Theodore R, Karin Knorr Cetina, and Eike von Savigny, editors 200I The Practice Turn in Contemporary Theory. Routledge: New York.

Silva, Noenoe K

2004 Aloha Betrayed: Native Hawaiian Resistance to American Colonialism. Durham, NC: Duke University Press.

Smith, Linda Tuhiwai

I999 Decolonizing Methodologies: Research and Indigenous People. New York: Zed Books.

Swidler, Ann

200I Talk of Love: How Culture Matters. Chicago: University of Chicago Press.

Teaiwa, Teresia K

200 Ia Militarism, Tourism and the Native: Articulations in Oceania. PhD

Dissertation, History of Consciousness, University of California, Santa Cruz.

200Ib Lo(o)sing the Edge. Contemporary Pacific I3:343-358.

Tengan, Ty Kāwika

2003 Hale Mua: (En)Gendering Hawaiian Men. PhD Dissertation, Anthropology, University of Hawai'i, Honolulu.

Trask, Haunani-Kay

I999 From a Native Daughter: Colonialism and Sovereignty in Hawai'i. Honolulu: University of Hawai'i Press.

Wendt, Albert

I976 Towards a New Oceania. Mana Review I (I): 49-60.

White, Geoffrey M

I99I Identity Through History: Living Stories in a Solomon Islands Society. Cambridge: Cambridge University Press.

2000 Histories and Subjectivities. Ethos 28 (2): 493-5Io.

Wood, Houston

I999 Displacing Natives: The Rhetorical Production of Hawai'i. Lanham, MD: Rowman and Littlefield. 
2003 Cultural Studies for Oceania. The Contemporary Pacific I 5:340-376. Young, Kanalu G Terry

I998 Rethinking the Native Hawaiian Past. New York: Garland Publishing.

\section{Abstract}

Three research perspectives are currently competing in Oceania. A disciplinebased perspective still dominates, though ever fewer people believe that disciplines produce superior forms of knowledge. An alternative, interpretation-based perspective is becoming more prominent, but this approach relies on confusing and contradictory claims about how interpretations connect to concrete activities. A practice-based approach seems better able to promote diversity and place-based autonomies in Oceania. Research that focuses on practices avoids the universalizing claims of discipline-based research. By treating cultures as dynamic repertoires of practices, a practice-based approach integrates interpretive and noninterpretive activities within a single research frame. Examples from many researchers, including Epeli Hau'ofa and Ty Kāwika Tengan, illustrate the benefits of a practice-based approach.

KEYWORDS: disciplines, Oceania, Pacific studies, practices, research 